
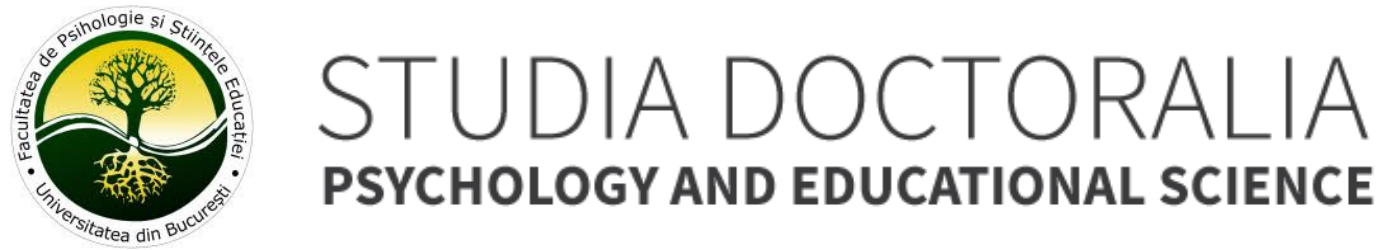

PSYCHOLOGY AND EDUCATIONAL SCIENCE

\title{
Trait Emotional Intelligence, Coping Strategies, and Self-Esteem in Romanian Adolescents
}

\author{
Sabina Alexandra Dumitrescu
}

University of Bucharest

\section{ARTICLE INFO}

\section{Article history:}

Received 04-March-2019

Accepted 25-April-2019

Available online 01-May-2019

This article should be cited as: Dumitrescu, S. A.. (2019). Trait Emotional Intelligence, Coping Strategies, and Self-Esteem in Romanian Adolescents. Studia Doctoralia. Psychology and Educational Science, 10, 52-60.

This is an open access article under the CC BY license (http://creativecommons.org/licenses/by/4.0/).

Corresponding author at: University of Bucharest, Department of Psychology, 90 Panduri Av, Bucharest, RO.

Tel.: +40 (0)722 648650 .

E-mail address: sabina.dumitrescu@gmail.com

\section{ABSTRACT}

In this study we have succeeded to render an authentic image of Romanian adolescents in terms of El, coping strategies, and self-esteem. The study involved 211 adolescents aged between 15 and 18, who attend high school in Bucharest. The aim of the study was to identify the relationships between El and coping strategies, El and self-esteem, but also the mediating role of self-esteem in the relationship between El and coping strategies. Three psychometric instruments were used: TEIQue ASF for the assessment of El, the Self-Perception Profile for Adolescents for self-esteem, and CERQ for coping strategies. The results have shown that El predicts the nature of the coping strategies chosen by adolescents when confronted with stressful situations. Also, self-esteem has proven to be a significant mediator only in the relationship between $\mathrm{El}$ and maladaptive coping, improving its effects, but not in the relationship between $\mathrm{El}$ and adaptive coping.

Keywords: emotional intelligence, coping strategies, selfesteem, adolescents

\section{INTRODUCTION}

This study aims to analyse the relationship between emotional intelligence, coping strategies and self-esteem in adolescents. Emotional intelligence has captured the attention of psychologists and specialists in the majority of the humanistic sciences. It is studied in relationship with gender, age, level of education, personality, interpersonal relationships or well-being and together with numerous other constructs that are part of the structure of the human psyche. 
In this study, we aim to analyse the relationships between emotional intelligence, coping strategies and self-esteem in adolescents.

Individuals with a high level of emotional intelligence are often described as being well-adapted to the environment, kind, original, persevering and optimistic (Salovey \& Mayer, 1990). At the same time, emotional intelligence entails a set of mental abilities that include high level processes: attention to feelings, clarity of feelings, the ability to discriminate among feelings and mood-regulatory strategies (Mayer \& Salovey, 1993). It has been ascertained that emotional intelligence is positively correlated with variables such as empathy, verbal intelligence, extraversion, openness to feelings, self-esteem and life satisfaction (Ciarrochi, Chan, \& Caputi, 2000; Mayer, Caruso and Salovey, 1999; Schutte et al., 1998), but also with various types of intelligence, such as cognitive abilities and social intelligence. Goleman (1995) believes that although cognitive abilities may contribute to the integration of the individuals within certain fields of activity, emotional intelligence plays an essential role in determining the level of success they will reach in the field in question. Goleman also claims that emotional intelligence plays a special role in forming and maintaining relationships, and Saarni (1999) claims that emotional competence represents a fundamental component of social development, contributing to the quality of interpersonal relationships.

Specialists' opinions regarding emotional intelligence (EI) are divided, but two solid approach directions have crystalized: ability El and trait El. These two directions are based on the idea that cognitive abilities are not the sole predictor of the optimum adaptation of individuals, which is why other aspects should also be taken into consideration, such as moods or emotional competences.

If conceptualized as a trait, emotional intelligence is defined through a constellation of emotional self-perceptions localized at the basic levels of the personality hierarchies (Petrides et al., 2007). If conceptualized as an ability, emotional intelligence strongly resembles social intelligence and is closely related to the ability to create and maintain interpersonal relationships.

The perspective that approaches El as an ability (Salovey \& Mayer, 1990) considers El to be a form of intelligence that can be measured through performance tests. At the opposite end, we have the perspective that approaches EI as a trait that can be measured through self-reports (Petrides \& Furnham, 2000). Trait El is an important variable in the studies conducted in the health, educational and organizational field. In terms of health, research has shown that trait El is associated with a higher resistance to stress (Salovey, Stroud, Woolery, \& Epel, 2002). In terms of education, El is a relevant trait both for pupils with bad results, as well as for pupils with good results. Therefore, pupils that have a low IQ, but a high EQ have better results in school and show less deviant behaviours (Petrides et al., 2004). Pupils with high IQ and high $E Q$ use more functional strategies to manage the distress caused by the differences between them and the other pupils (Chan, 2003).

\section{Emotional intelligence and coping strategies}

People with high EQ strongly believe in self-efficacy regarding the regulation of their own emotions and believe they have the necessary resources to overcome negative states that accompany stressful events. Thus, they manage to focus on coping and to minimize the inauspicious influences of the stressful situations.

According to the transactional model (Lazarus \& Folkman, 1984), stress originates in the interaction between the person and the environment. Stressful situations produce a subjective lack of balance between the requirements of the individual and the resources necessary to satisfy such requirements. Coping with such situations occurs as a process of managing the internal and external requirements that the person assesses as threatening. Emotional activation is accompanied by a specific assessment of the situation, immediate and automatic, which confers the cognitive basis that triggers the occurrence of emotions and which in turn determines the level of stress experienced. Thus, appraisals, emotions and coping strategies are constantly interacting and interchanging.

Adaptive coping strategies protect the individual by eliminating or remodelling the conditions that generated the stress or by maintaining the emotional responses within easily managed or controlled limits. Thus, managing negative emotions and dysfunctional cognitions that occur throughout stressful situations is essential for an efficient coping.

Through coping strategies, the person acts in order to counteract or diminish the source of stress or to improve the afferent negative emotions. Lazarus and Folkman (1984) have described three categories of coping strategies. The first category lists the strategies centred on the problem, its resolution and changing the external reality, ultimately aiming to influence the source of stress and to implicitly reduce tension. The second category includes the strategies centred on emotions consisting in reconsidering the stressful emotions and reconceptualising the problem in order to diminish tension. The third category includes the avoidance strategies, the tendency to reduce tensions by distancing oneself from the problem. Carver, Scheier, \& Pozo (1989), following a factorial analysis, have extended this structure and have divided coping strategies into adaptive strategies (active coping, planning, looking for social support) and maladaptive strategies (denial, rumination, blaming and selfblaming, behavioural detachment, catastrophizing). Salovey et al. (2000) claim that the more varied the repertoire of coping strategies, the greater their effectiveness is. An 
individual's ability to cope and adjust depends on the level of integration of emotional and cognitive functions.

The multitude of emotional abilities present in El allows the individual to acquire a basis of knowledge that will help them manage stressful situations. The higher the level of El, the more efficient their coping strategies will be, and the lower their level of $\mathrm{El}$, the more their maladaptive strategies will become the results of their difficulties in processing the emotional material (Matthews \& Zeidner, 2000). Adaptive strategies help a person channel their negative emotions constructively through accurate perception and the understanding and regulation of such negative emotions.

Persons with high EQ will create a less stressful environment and will try to manage their life in such a manner as to experience as few frustrating events as possible. El represents a personal state that precedes adaptive coping, which acts through hard to define processes but which determine an effective management of emotional challenges (Salovey, Stroud, Woolery, \& Epel, 2002).

Taking into consideration the above-mentioned, we assume that adolescents with higher levels of El would cope with stressful situations in a more adaptive manner, as compared to adolescents with lower levels of El. We thus formulate the first two hypotheses of this study:

\section{H1. A high level of El predicts the usage of adaptive coping} strategies within adolescents.

H2. A low level of El predicts the usage of maladaptive coping strategies within adolescents.

\section{Emotional intelligence and self-esteem}

Together with El, self-esteem is a key factor in the welladaption of adolescents and in the forming of adaptive coping strategies.

Self-esteem is considered to be an emotional response, a general feeling regarding one's person. It can be viewed as a function of success in the social environment (success vs. failure). In adolescents, social competence, quality interpersonal relationships, popularity and school reputation are the essential ingredients that facilitate the forming of self-esteem.

Schutte et al. (2002) claimed that individuals with higher El use the abilities to understand and regulate their emotions in order to cope with situational threats. They can thus maintain a positive mood when needed and to "fix" a negative mood caused by their being confronted with possible adverse events. This emotional ability leads to the preservation of high levels of self-esteem or to a positive self-perception. The authors have thus concluded that a high level of El is associated with an increase in positive mood and self-esteem, even after experiencing negative events.

In samples of adolescents, the studies have shown that high El scores are positively correlated with self-image and with positive appraisal of one's value (Ciarrochi, Chan, \& Bajgar, 2001; Fernandez-Berrocal et al., 2006). The contribution of emotional intelligence to self-esteem is plausible because high levels of emotionality and sociability determine the adolescents to feel good about themselves and to be proud of what they are.

Taking into consideration the above-mentioned, we establish the third hypothesis of this study:

\section{H3. A high level of El predicts a higher self-esteem.}

\section{Emotional intelligence, self-esteem and coping strategies}

Numerous studies have showed that self-esteem is connected to coping strategies. Therefore, a low level of self-esteem may lead to low performances, negative affective states and motivational deficit, which leads to a diminishing of the capacity to successfully manage stressful situations (Ader et al., 1991). Self-esteem may also influence the coping strategies that focus on the problem and which may lead to choosing maladaptive strategies. The teenagers' preoccupation with low self-esteem towards their own sadness may lead to the inhibition of their involvement in assertive and adaptive actions to combat stress.

While a high level of El facilitates the approaching of adaptive coping strategies, self esteem may interfere in this relationship and may accentuate the selection of this type of strategies or may reduce the selection of maladaptive strategies. As long as self-esteem represents the selfperception and positive assessment of one's capacities, it may influence the effects El has on selecting the coping strategies.

By taking into consideration the above-mentioned, we establish the fourth hypothesis of this study:

H4. Self-esteem mediates the relationship between El and coping strategies. 


\section{METHODOLOGY}

\section{Participants and procedure}

The participants were 211 adolescents aged between 15 and 18 attending a high school in Bucharest, $M=16.37, S D$ $=.70$. Of them, 97 are boys (46\%), and 114 are girls (54\%). The participants were invited to take part in a study, with the school's consent and the informed consent of their parents. The assessment was carried out in classrooms during the normal school schedule. The adolescents were informed that their data will be kept anonymous and confidential and that they can withdraw from the study anytime they wanted. The questionnaires were administered in paper and pencil format. No incentive was offered for participation.

The study is cros-sectional, correlational.

\section{Instruments}

1. Trait Emotional Intelligence Questionnaire Adolescents Short Form (TEIQue ASF; Petrides \& Furnham, 2003). The questionnaire provides an operationalization which conceptualizes $\mathrm{El}$ in terms of personality. The variant we used is made of 30 items organized into four subscales: well-being, self-control, emotionality and sociability. The answers are given on a seven point Likert scale where 1 represents total disagreement and 7 represents total agreement. The subscale scores are determined by calculating the arithmetic mean for the scores recorded for the items in question. Example of an item: "I find it easy to talk to other people about my feelings". Following the analysis of internal consistency, a Cronbach Alpha coefficient, $a=.85$, was obtained.

2. Self-Perception Profile for Adolescents (SPPA; Messer \& Harter, 2012). The instrument was developed as a response to the need for a psychometric tool that would adequately reflect the multidimensional complexity of the adolescents' self. Eight specific fields plus global self esteem were included in the scale for adolescents. The tool measures nine specific dimensions: scholastic competence, social competence, athletic competence, physical appearance, job competences, romantic appeal, behavioural conduct, close friendship and global self-esteem. The response variants

\section{RESULTS}

For data analyses we used IBM SPSS 24 (IBM Corp, 2016) and Medmod module of JAMOVI (The jamovi project, 2019). are thus presented in a manner that leads a person to first select between two extremes, and then one of the two intensities. The adolescent scale uses structured alternatives that were designed to prevent socially desirable answers. Two or three positive items and respectively, two or three negative items were formulated, thus suggesting that half of the people in the entire world felt both ways. The participants must select which type of adolescent is closer to them. This type of format legitimates any choice. They will then show how true is one of the two claims for them. The "sort of true for me" and "really true for me" options widen the range of choices in comparison with the typical format of two choices. The scale contains 45 items. Each of the nine subscales contains five items. In each subscale, half of the items are formulated so as the first part would reflect high competence or adequacy and the other part would reflect incompetence or low adequacy. The questionnaire is also called "As I am”. Example of an item: „Some adolescents make friends easily." The items were assigned values of four, three, two or one, where 4 is the most competent or adequate self assessment, and 1 is the least competent or adequate self assessment. The subscale scores are obtained by adding the items of each subscale.

In this study we used only the global self-esteem subscale (5 items). Following the analysis of internal consistency, a Cronbach Alpha coefficient, $a=.83$, was obtained.

3. Cognitive Emotion Regulation Questionnaire (CERQ; Garnefski et al., 2001). The cognitive-emotional coping questionnaire is a multidimensional questionnaire developed to identify the cognitive coping strategies that one would use after experiencing certain negative events or situations. CERQ is a self-assessment questionnaire with 36 items organized into nine subscales: self-blame, acceptance, rumination, refocus on planning, positive reappraisal, putting into perspective, catastrophizing and other-blame. Answers are given on a five point Likert scale, where 1 means never and 5 means always. Example of an item: „I feel like I am to blame for what happened". Following the analysis of internal consistency, a Cronbach Alpha coefficient, $\alpha=.85$, was obtained.

The descriptive statistics are presented in Table 1. 
Table 1. Means, standard deviations, skewness and kurtosis

\begin{tabular}{lrrrr}
\hline & M & \multicolumn{1}{c}{ SD } & \multicolumn{1}{c}{ Skewness } & \multicolumn{1}{c}{ Kurtosis } \\
\hline Well-being & 5.36 & 1.34 & -.83 & .26 \\
Self-control & 4.38 & .97 & -.47 & .39 \\
Emotionality & 4.61 & .88 & -.10 & -.07 \\
Sociability & 5.03 & .81 & -.54 & .46 \\
El & 4.84 & .73 & -.24 & -.29 \\
Self-esteem & 3.05 & .68 & -.65 & -.11 \\
Self-blame & 11.35 & 3.10 & .71 & .29 \\
Acceptance & 13.53 & 3.29 & -.14 & -.29 \\
Rumination & 13.73 & 3.93 & -.19 & -.63 \\
Positive refocus & 10.17 & 4.23 & .58 & -.11 \\
Refocus on planning & 15.50 & 3.34 & -.52 & -.33 \\
Positive reappraisal & 13.91 & 3.80 & -.19 & -.76 \\
Putting into perspective & 12.15 & 4.05 & .160 & -.726 \\
Catastrophizing & 7.90 & 3.12 & .899 & .407 \\
Other-blame & 8.32 & 2.72 & .835 & 1.375 \\
\hline
\end{tabular}

\section{Hypothesis testing}

H1. A high level of El predicts the usage of adaptive coping strategies within adolescents.

In order to test $\mathrm{H} 1$, a multiple regression analysis was conducted having as predictors the four dimensions of El and as dependent variable the adaptive coping strategies.

Table 2. Regression model for El as a predictor of adaptive coping strategies

\begin{tabular}{|c|c|c|c|c|c|c|}
\hline \multirow[b]{2}{*}{ Model } & & \multicolumn{2}{|c|}{ Unstandardized Coefficients } & $\begin{array}{c}\text { Standardized } \\
\text { Coefficients }\end{array}$ & \multirow[b]{2}{*}{$\mathrm{t}$} & \multirow[b]{2}{*}{ Sig. } \\
\hline & & B & Std. Error & Beta & & \\
\hline 1 & (Constant) & 7.233 & 1.289 & & 5.612 & .000 \\
\hline & Well-being & .282 & .157 & .146 & 1.800 & .073 \\
\hline & Self-control & .140 & .197 & .052 & .709 & .479 \\
\hline & Emotionality & .866 & .211 & .291 & 4.105 & .000 \\
\hline & Sociability & -.054 & .228 & -.017 & -.239 & .812 \\
\hline
\end{tabular}

a. Dependent Variable: Adaptive coping

b. $R^{2}=.15$

It was noticed that El predicts $15.4 \%$ of the adaptive coping strategies. The regression equation is statistically significant, $F(4,205)=9.331, p=.00$. Of the four dimensions of El, only emotionality significantly predicts the adaptive coping strategies, $\beta=.29, p=.00$. It can be said that a high level of emotionality as an El dimension determines an increase in the adopting of adaptive coping strategies.
H2. A low level of El predicts the usage of maladaptive coping strategies within adolescents.

In order to test $\mathrm{H} 2$, a multiple regression analysis was conducted, having as predictors the four dimensions of EI and as dependent variable the maladaptive coping strategies.

Table 3. Regression model for El as a predictor of maladaptive coping strategies

\begin{tabular}{|c|c|c|c|c|c|c|}
\hline \multirow[b]{2}{*}{ Mode } & & \multicolumn{5}{|c|}{$\begin{array}{l}\text { Standardized } \\
\text { Coefficients }\end{array}$} \\
\hline & & B & Std. Error & Beta & $t$ & Sig. \\
\hline \multirow[t]{5}{*}{1} & (Constant) & 13.721 & .961 & & 14.283 & .000 \\
\hline & Well-being & -.436 & .117 & -285 & -3.731 & .000 \\
\hline & Self-control & -.740 & .147 & -.349 & -5.046 & .000 \\
\hline & Emotionality & .466 & .157 & .198 & 2.968 & .003 \\
\hline & Sociability & .006 & .170 & .002 & .037 & .970 \\
\hline
\end{tabular}

a. Dependent Variable: Maladaptive coping

b. $R^{2}=.25$ 
It was noticed that El predicts $25 \%$ of maladaptive coping strategies. The regression equation is statistically significant, $F(4,205)=17.056, p=.00$. Of the four $\mathrm{El}$ dimensions, only sociability does not significantly predict maladaptive coping strategies. Thus, well-being and selfcontrol negatively predict maladaptive coping strategies, $\beta=$ $-.285, p=.00$, respectively $\beta=-.349, p=.00$, and emotionality positively predicts maladaptive coping strategies, $\beta=.198, p=.00$. We could say that an increase in well-being and self-control as El dimensions will lead to a decrease in the selection of maladaptive coping strategies. At the same time, a high level of emotionality will determine an increase in the selection of maladaptive coping strategies.

\section{H3. A high level of El predicts a higher self-esteem.}

In order to test $\mathrm{H} 3$, a multiple regression analysis was conducted, having as predictors the four dimensions of EI and as dependent variable self-esteem.

Table 4. Regression model for El as a predictor of self-esteem

\begin{tabular}{|c|c|c|c|c|c|c|}
\hline & & Unstandardize & oefficients & $\begin{array}{c}\text { Standardized } \\
\text { Coefficients }\end{array}$ & & \\
\hline & & B & Std. Error & Beta & $\mathrm{t}$ & Sig. \\
\hline 1 & (Constant) & .826 & .253 & & 3.263 & .001 \\
\hline & Well-being & .330 & .031 & .653 & 10.704 & .000 \\
\hline & Self-control & .067 & .039 & .096 & 1.737 & .084 \\
\hline & Emotionality & .016 & .041 & .020 & .376 & .707 \\
\hline & Sociability & .018 & .045 & .022 & .413 & .680 \\
\hline
\end{tabular}

\section{a. Dependent Variable: Self-esteem}

b. $R^{2}=.52$

It was noticed that El predicts $52 \%$ of self-esteem. The regression equation is statistically significant, $F(4,205)=$ $55.710, p=.00$. Of the four dimensions of El, only well being significantly predicts self-esteem, $\beta=.653, p=.00$. It can be said that an increase in well-being as an El dimension will lead to a decrease in self-esteem.
H4. Self-esteem mediates the relationship between El and coping strategies.

In order to test this hypothesis, a series of mediation analyses were conducted, using global El as predictor and coping strategies as dependent variable, alternatively. The mediating variable was self-esteem.

Table 5. Mediation estimate for self-esteem as a mediator in the relationship between El and adaptive coping strategies

\begin{tabular}{|c|c|c|c|c|c|c|c|c|}
\hline \multirow[b]{2}{*}{ Effect } & \multirow[b]{2}{*}{ Label } & \multirow[b]{2}{*}{ Estimate } & \multirow[b]{2}{*}{ SE } & \multicolumn{2}{|c|}{ 95\% Confidence Interval } & \multirow[b]{2}{*}{ Z } & \multirow[b]{2}{*}{$p$} & \multirow[b]{2}{*}{$\%$ Mediation } \\
\hline & & & & Lower & Upper & & & \\
\hline Indirect & $a \times b$ & 0.0108 & 0.153 & -0.289 & 0.310 & 0.0709 & 0.943 & 1.10 \\
\hline Direct & c & 0.9731 & 0.272 & 0.439 & 1.507 & 3.5737 & $<.001$ & 98.90 \\
\hline Total & $c+a \times b$ & 0.9839 & 0.225 & 0.542 & 1.426 & 4.3663 & $<.001$ & 100.00 \\
\hline
\end{tabular}

Table 6. Path estimate for self-esteem as a mediator in the relationship between El and adaptive coping strategies

\begin{tabular}{|c|c|c|c|c|c|c|c|c|c|}
\hline & & & \multirow[b]{2}{*}{ Label } & \multirow[b]{2}{*}{ Estimate } & \multirow[b]{2}{*}{ SE } & \multicolumn{2}{|c|}{ 95\% Confidence Interval } & \multirow[b]{2}{*}{ Z } & \multirow[b]{2}{*}{$p$} \\
\hline & & & & & & Lower & Upper & & \\
\hline IE & $\rightarrow$ & STIM & a & 0.5589 & 0.0567 & 0.448 & 0.670 & 9.8533 & $<.001$ \\
\hline STIM & $\rightarrow$ & STAD & $\mathrm{b}$ & 0.0194 & 0.2735 & -0.517 & 0.555 & 0.0709 & 0.943 \\
\hline IE & $\rightarrow$ & STAD & c & 0.9731 & 0.2723 & 0.439 & 1.507 & 3.5737 & $<.001$ \\
\hline
\end{tabular}


Table 7. Mediation estimate for self-esteem as a mediator in the relationship between El and maladaptive coping strategies

\begin{tabular}{|c|c|c|c|c|c|c|c|c|}
\hline \multirow[b]{2}{*}{ Effect } & \multirow[b]{2}{*}{ Label } & \multirow[b]{2}{*}{ Estimate } & \multirow[b]{2}{*}{ SE } & \multicolumn{2}{|c|}{ 95\% Confidence Interval } & \multirow[b]{2}{*}{$\mathbf{Z}$} & \multirow[b]{2}{*}{$\mathbf{p}$} & \multirow[b]{2}{*}{$\%$ Mediation } \\
\hline & & & & Lower & Upper & & & \\
\hline Indirect & $a \times b$ & -0.328 & 0.122 & -0.567 & -0.0884 & -2.68 & 0.007 & 36.2 \\
\hline Direct & c & -0.578 & 0.209 & -0.988 & -0.1679 & -2.76 & 0.006 & 63.8 \\
\hline Total & $c+a \times b$ & -0.905 & 0.176 & -1.251 & -0.5599 & -5.14 & $<.001$ & 100.0 \\
\hline
\end{tabular}

Table 8. Path estimate for self-esteem as a mediator in the relationship between El and maladaptive coping strategies

\begin{tabular}{|c|c|c|c|c|c|c|c|c|c|}
\hline & & & \multirow[b]{2}{*}{ Label } & \multirow[b]{2}{*}{ Estimate } & \multirow[b]{2}{*}{ SE } & \multicolumn{2}{|c|}{ 95\% Confidence Interval } & \multirow[b]{2}{*}{$\mathbf{Z}$} & \multirow[b]{2}{*}{$\mathbf{p}$} \\
\hline & & & & & & Lower & Upper & & \\
\hline IE & $\rightarrow$ & STIM & a & 0.559 & 0.0567 & 0.448 & 0.670 & 9.85 & $<.001$ \\
\hline STIM & $\rightarrow$ & STDEZ & b & -0.586 & 0.2100 & -0.998 & -0.174 & -2.79 & 0.005 \\
\hline IE & $\rightarrow$ & STDEZ & c & -0.578 & 0.2091 & -0.988 & -0.168 & -2.76 & 0.006 \\
\hline
\end{tabular}

It is noticed that self-esteem fails to mediate the relationship between El and adaptive coping ( $p>$.05). On the other hand, El mediates the relationship between $\mathrm{El}$ and maladaptive coping strategies, the mediation percentage being of $36.2 \%\left(a^{*} b=.33, p<.001\right)$. El increases the level

\section{DISCUSSION}

The results of this study have shown that El is associated with coping strategies in the meaning that adolescents with high El will choose adaptive coping strategies while adolescents with low El will choose maladaptive coping strategies. The single El dimension which predicted adaptive coping was emotionality and the dimensions of El predicting maladaptive coping were well-being, self-control and emotionality.

Thus, the El dimensions facilitating the selection of adaptive coping strategies differ from those that lead to the selection of maladaptive strategies. The high level of emotionality predisposes adolescents to positive refocus, refocus on planning, putting into perspective, positive reappraisal of the stressful situations, methods of a healthy rationalization and balanced relating to the problems faced. On the other hand, well-being and self-control have negative effects on maladaptive coping strategies, diminishing the self-blame, rumination, catastrophizing or other-blame strategies. At the same time, emotionality makes adolescents internalise more intensely and profoundly the effects of the stressful of self-esteem, and self-esteem diminishes the adolescents' tendency to choose maladaptive coping strategies.strategies, the indirect effect being statistically significant.

situations. In the end, emotional sensibility is a type of connection with others but also an openness to others, thus leaving a gate opened for adverse events and increasing permeability to stress. A high level of emotionality may thus also lead to the selection of maladaptive coping strategies. In what regards self-esteem, El has proven a significant predictor only through its well-being dimension, which shows that adolescents with high well-being will also have a high self-esteem.

The results obtained in this study are also congruent with those obtained by other specialists. Thus, in Great Britain, Petrides et al. (2007) have shown that trait El is associated with rumination, dysfunctional attitudes, coping and psychological adaptation even when personality traits are controlled. Downey et al. (2010), in a study involving Australian teenagers, have shown that recognizing, understanding and expressing emotions is associated with using coping strategies that focus on the problem. In a study conducted in Italy, trait El turned out to be a predictor of dysfunctional emotional adaptation in teenagers, after 
controlling personality traits, non-verbal cognitive ability and gender (Andrei et al., 2014). In Belgium, Mikolajczac and Luminet (2008) have shown that adolescents with high level of trait El show a greater capacity to assess stressful situations and to cope with them. Moreover, the authors have ascertained that El determines the selection of adaptive coping strategies in situations of fear, shame, anger, sadness or jealousy and that adolescents choose adaptive strategies in order to feel good.

As a mediator in the relationship between El and coping strategies, self-esteem has turned out to only bear effects in the case of maladaptive coping strategies, which shows that adolescents that have learned and manage to healthily adapt to the stressful situations they are confronted with will also manage to do it in the absence of high self-esteem. On the other hand, adolescents choosing maladaptive coping strategies require a high level of self-esteem to diminish their tendency to choose such strategies.

These results may be of high importance in the applicative field, since school counsellors or psychotherapists or even educators and parents may intervene on self-esteem in order to improve the children's manner of coping.

El seems to be significant not for building adaptive coping strategies, but for diminishing the maladaptive coping strategies. This observation shows that coping strategies develop early, before emotional intelligence and independently of it. El's role in this equation is to improve the

\section{REFERENCES}

Andrei, F., Mancini, G., Trombini, E., Baldaro, B., and Russo, P. M. (2014). Testing the incremental validity of Trait Emotional Intelligence: evidence from an Italian sample of adolescents. Personality and Individual Differences, 64, 24-29.

Carver, C. S., Scheier, M. F., \& Pozo, C. (1992). Conceptualizing the process of coping with health problems. In H. S. Friedman (Ed.), Hostility, coping and health (pp. 167-199). Washington, DC: American Psychological Association.

Chan, D. W. (2003). Dimensions of emotional intelligence and their relationships with social coping among gifted adolescents in Hong Kong. Journal of Youth and Adolescence, 32, 409-418.

Ciarrochi, J. V., Chan, A. Y. C., Caputi, P. (2000). A critical evaluation of the emotional intelligence construct. Personality and Individual Differences, 28, 539-561.

Ciarrochi, J. V., Chan, A., \& Bajgar, J. (2001). Measuring emotional intelligence in adolescents. Personality and Individual Differences, 31, 1105-1119.

Downey, L. A., Johnston, P. J., Hansen, K., Birney, J., and Stough, C. (2010). Investigating the mediating effects of inauspicious effects of selecting dysfunctional strategies. Therefore, the El development programs for children and adolescents may be of high importance in their healthy development.

\section{Limitations and further research}

One of the limitations of this study is that the adolescents come from the same high school, the same environment, and have relatively similar life conditions, which leads to the impossibility of generalizing the results obtained to other categories of adolescents, possibly from the rural environment or coming from families with a much lower or a much higher income. The socio-demographic variables, as well the personal characteristics of the adolescents may constitute key study elements in further research.

Another limitation of the study is the self-administered questionnaires, because adolescents may tend to offer desirable answers solely to make a good impression.

In future studies, we aim to establish the relationships between $\mathrm{El}$, coping strategies and self-perception in adolescents, by analysing more deeply not only self-esteem, but also the self perceptions of adolescents (scholastic competence, social competence, athletic competence, etc.). insecurity.

emotional intelligence and coping on problem behaviours in adolescents. Australian Journal of Psychology, 62, 20 29.

Fernández-Berrocal, P., Alcaide, R., Extremera, N., \& Pizarro, D. A. (2006). The role of emotional intelligence in anxiety and depression among adolescents. Individual Differences Research, 4, 16-27.

Garnefski, N., Kraaij, V., \& Spinhoven, P. (2002). Manual for the use of the Cognitive Emotion Regulation Questionnaire.Lei-derdorp, The Netherlands: DATEC.

Goleman, D. (1995). Emotional Intelligence. New York: Bantam Books.

Lazarus, R. S., \& Folkman, S. (1984). Stress, appraisal and coping. New York: Springer.

Matthews, G., \& Zeidner, M. (2000). Emotional intelligence, adaptation to stressful encounters and health outcomes. In R. Bar-On, \& J. D. Parker (Eds.), Handbook of emotional intelligence (pp. 459-489). New York: JosseyBass.

Mayer, J. D., \& Salovey, P. (1993). The intelligence of emotional intelligence. Intelligence, 17, 433-442. 
Mayer, J. D., Caruso, D. R., \& Salovey, P. (1999). Emotional intelligence meets traditional standards for an intelligence. Intelligence, 27(4), 267-298.

Messer, B., \& Harter, S. (2012). The Adolescent SelfPerception Profile. Denver: University of Denver.

Mikolajczak, M., Luminet, O. (2008). Trait emotional intelligence and the cognitive appraisal of stressful events: an exploratory study. Personality and Individual Differences, 44, 1445-1453.

Petrides, K. V., \& Furnham, A. (2000). Gender differences in measured and self-estimated trait emotional intelligence. Sex Roles, 42(5-6), 449-461.

Petrides, K. V., Frederickson, N., \& Furnham, A. (2004). The role of trait emotional intelligence in academic performance and deviant behavior at school. Personality and Individual Differences, 36, 277-293.

Petrides, K. V., Pérez-González, J. C., and Furnham, A. (2007). On the criterion and incremental validity of trait emotional intelligence. Cognition \& Emotion, 21, 26-55.

Saarni, C. (1999). The development of emotional competence. New York: Guilford Press
Salovey, P., \& Mayer, J. (1990). El. Imagination, Cognition and Personality, 9, 185-211.

Salovey, P., Stroud, L. R., Woolery, A., \& Epel, E. S. (2002). Perceived emotional intelligence, stress reactivity, and symptom reports: Further explorations using the trait meta-mood scale. Psychology \& Health, 17, 611-627.

Salovey, P., Bedell, R. T., Detweiler, J., \& Mayer, J. (2000). Current directions in emotional intelligence research. In M. Lewis, \& J. M. Haviland-Jones (Eds.), Handbook of emotions (pp. 504-520). New York: Guilford.

Schutte, N. S., Malouff, J. M., Hall, L. E., Haggerty, D. J., Cooper, J. T., Golden, C. J., Dornheim, L. (1998). Development and validation of a measure of emotional intelligence. Personal and Individual Differences, 25, 167177.

Schutte, N. S., Malouff, J., Simunek, M., Hollander, S., \& McKenley, J. (2002). Characteristic emotional intelligence and emotional well-being. Cognition and Emotion, 16, 769-785. 